\title{
HPLC/APCI Mass Spectrometry of Saturated and Unsaturated Hydrocarbons by Using Hydrocarbon Solvents as the APCI Reagent and HPLC Mobile Phase
}

\author{
Jinshan Gao, Benjamin C. Owen, David J. Borton II, Zhicheng Jin, Hilkka I. Kenttämaa
} Department of Chemistry, Purdue University, West Lafayette, IN 47907, USA

\begin{abstract}
Saturated and unsaturated, linear, branched, and cyclic hydrocarbons, as well as polyaromatic and heteroaromatic hydrocarbons, were successfully ionized by atmospheric pressure chemical ionization (APCl) using small hydrocarbons as reagents in a linear quadrupole ion trap (LQIT) mass spectrometer. Pentane was proved to be the best reagent among the hydrocarbon reagents studied. This ionization method generated different types of abundant ions (i.e., $[\mathrm{M}+\mathrm{H}]^{+}$, $\mathrm{M}^{+*},[\mathrm{M}-\mathrm{H}]^{+}$and $[\mathrm{M}-2 \mathrm{H}]^{+}$), with little or no fragmentation. The radical cations can be differentiated from the even-electron ions by using dimethyl disulfide, thus facilitating molecular weight (MW) determination. While some steroids and lignin monomer model compounds, such as androsterone and 4-hydroxy-3-methoxybenzaldehyde, also formed abundant $\mathrm{M}^{+\bullet}$ and $[\mathrm{M}+\mathrm{H}]^{+}$ions, this was not true for all of them. Analysis of two known mixtures as well as a base oil sample demonstrated that each component of the known mixtures could be observed and that a correct MW distribution was obtained for the base oil. The feasibility of using this ionization method on the chromatographic time scale was demonstrated by using high-performance liquid chromatography (HPLC) with hexane as the mobile phase (and APCl reagent) to separate an artificial mixture prior to mass spectrometric analysis.
\end{abstract}

Key words: APCI, Saturated hydrocarbons, Hydrocarbon solvents, Hydrocarbon reagents, HPLC

\section{Introduction}

$\mathrm{T}$ he molecular-level characterization of complex mixtures of organic molecules, such as biofuels [1-3], is still a great analytical challenge. Several methods have been introduced for the analysis of such mixtures, including NMR [4], FT-IR [5], GC/MS (electron ionization at $70 \mathrm{eV}$ ) [6], HPLC/MS (atmospheric pressure chemical ionization)

Electronic supplementary material The online version of this article (doi:10.1007/s13361-012-0347-5) contains supplementary material, which is available to authorized users.

Correspondence to: Hilkka I. Kenttämaa; e-mail: hilkka@purdue.edu
[7], ion chromatography [8], electrospray ionization (ESI) mass spectrometry [9], and ambient sonic-spray ionization (SSI) mass spectrometry $[10,11]$. From these methods, those involving mass spectrometry are the only approaches that yield molecular level information for the mixtures. Furthermore, mass spectrometry provides structural as well as molecular weight (MW; defined here as the mass of a single isotopically pure molecule composed of the most common isotopes, as opposed to average MW) information for the mixture components. Unfortunately, the mass spectrometric characterization of hydrocarbons and their mixtures, such as biofuels, is challenging due to the shortcomings of current ionization methods. For example, ESI [12], SSI [10, 11], and matrix-assisted laser desorption/ionization [13] (MALDI) are 
limited to ionization via protonation, deprotonation, and cation attachment $[14,15]$, which means that these methods cannot ionize analytes without easily ionizable functional groups, such as saturated hydrocarbons [16, 18]. Ambient analysis of saturated hydrocarbons by using dischargeinduced oxidation in desorption electrospray ionization (DESI) has been reported [19]. However, this method generates many different ions for each analyte, thus hindering MW determination for complex mixtures. Electron ionization (EI) produces severe fragmentation, which often prevents obtaining molecular weight information [20]. Field desorption (FD) and field ionization (FI) involve rapid heating of the analytes, which can cause fragmentation, especially for highly branched hydrocarbons [21]. This method also suffers from a bias against small and large analytes. Atmospheric pressure photoionization (APPI) can ionize nonpolar polycyclic aromatic hydrocarbons but it cannot be used to ionize saturated hydrocarbons [22]. Laserinduced acoustic desorption (LIAD)/Fourier-transform ion cyclotron resonance mass spectrometry (FT-ICR) using $\mathrm{ClMn}\left(\mathrm{H}_{2} \mathrm{O}\right)^{+}$as the chemical ionization reagent ion has been reported to allow the evaporation and ionization of nonpolar hydrocarbons without fragmentation under ultrahigh vacuum, but this approach requires special instrumentation $[16,17]$.

APCI was developed in the 1970 s, and was initially called atmospheric pressure ionization [23]. In an APCI source, corona discharge is used to ionize gases, such as $\mathrm{He}$, $\mathrm{N}_{2}$, or $\mathrm{CO}_{2}$, to form radical cations in the positive ion mode [23-25]. These ions collide with vaporized solvent molecules to form secondary reagent ions, usually $[\mathrm{M}+\mathrm{H}]^{+}, \mathrm{M}^{+\bullet}$, and/or $[\mathrm{M}-\mathrm{H}]^{+}$, and their solvent molecule clusters [25]. These reagent ions ionize the analyte by, for example, proton transfer, electron transfer, or hydride abstraction in positiveion mode APCI $[25,26]$. Saturated hydrocarbons can be ionized by using this method. Unfortunately, fragment ions are commonly formed. The same is true when using $\mathrm{CS}_{2}$ as an APCI reagent to form molecular ions for saturated hydrocarbons [27, 28] due to the low fragmentation threshold energies of their molecular ions. Recently, helium ionization mass spectrometry was implemented on a modified atmospheric-pressure ion source designed for electrospray ionization for ionization of aliphatic hydrocarbons [29]. This method allowed the ionization of saturated hydrocarbons to yield $[\mathrm{M}-\mathrm{H}]^{+}$ions with no associated fragmentation (unsaturated hydrocarbons, however, yielded protonated molecules). Hence, this is the most promising of the above methods.

Unfortunately, helium ionization mass spectrometry cannot be coupled with high-performance liquid chromatography (HPLC), which is often needed before mass spectrometric analysis of very complex mixtures, such as biofuels. However, it should be possible to use a nonpolar alkane solvent as the reagent gas in APCI. This would enable the use of HPLC to separate mixture components prior to mass spectrometric analysis. This paper introduces a mass spectrometric analysis method based on APCI with hydrocarbon reagents. This method yields abundant ions for saturated hydrocarbons with little or no fragmentation. Implementation to HPLC/mass spectrometry is also described.

\section{Experimental}

All chemicals were purchased from Sigma-Aldrich (St. Louis, MO, USA) and used without further purification. Thermo-Fisher Scientific (Waltham, MA, USA) linear quadrupole ion trap mass spectrometer (LQIT) coupled with atmospheric pressure chemical ionization (APCI) was employed in these experiments, as well as a Thermo Surveyor MS plus HPLC. Thermo-Fisher Scientific LTQ FT Ultra, a 7 Tesla hybrid linear quadrupole ion trap and Fourier-transform ion cyclotron resonance mass spectrometer (LQIT/FT-ICR), was also employed in order to do measurements at ultra-high resolution when necessary. Data analysis was carried out with Xcalibur 2.0.7 SP1. All analytes were successfully dissolved $(1.0-1.5 \mathrm{mg} / \mathrm{mL}$ solutions) in hydrocarbons (pentane, hexane, and cyclohexane), with the exception of the polyaromatic hydrocarbons and polar compounds, which needed sonication to dissolve (concentration was lower than $1.0 \mathrm{mg} / \mathrm{mL}$ ) or did not dissolve at all.

The APCI conditions were as follows: vaporizer temperature $150-250{ }^{\circ} \mathrm{C}$, capillary temperature $200-300{ }^{\circ} \mathrm{C}$, sheath gas $\left(\mathrm{N}_{2}, \mathrm{He}\right.$, or $\left.\mathrm{CO}_{2}\right)$ flow rate $20-40$ (arbitrary units), auxiliary and sweep gas flow rates 5-20 (arbitrary units), and direct injection flow rate $15-30 \mu \mathrm{L} / \mathrm{min}$. For HPLC/APCI analyses, typically a $10 \mu \mathrm{L}$ volume of an analyte solution $(1 \mathrm{mg} / \mathrm{mL})$ was injected into the HPLC-MS for analysis. The column used was an XBridge C18 column (dimensions $150 \times 2.1 \mathrm{~mm}$, particle size $3.5 \mu \mathrm{m}$, Waters (Milford, MA, USA)). Hexanes were employed as the mobile phase and were eluted at a flow rate of $0.2 \mathrm{~mL} / \mathrm{min}$. The entire eluent was delivered into and ionized by APCI and the analytes were detected by LQIT. The product ions' branching ratios are reproducible within 5\%. Collisionactivated dissociation (CAD) was performed by resonance excitation of the selected ions for $30 \mathrm{~ms}$. The "normalized CAD energy" was 12-30 (arbitrary units).

\section{Results and Discussion}

The ability to utilize saturated hydrocarbons as APCI reagents was probed by analyzing model compounds of different types (Table S1 in Supplemental Information). The saturated hydrocarbons studied are structurally similar to compounds that may be present in second generation biodiesel [30]. Several polar compounds were also studied, including steroids and lignin monomer model compounds. Similar results, with a few exceptions discussed below, were obtained by using pentane, hexane, or cyclohexane as the APCI reagent. The mass spectra measured for each analyte are discussed below. After that, results obtained using 
different sheath gases and the analyses of two known mixtures and a base oil sample are discussed.

$[\mathrm{M}-\mathrm{H}]^{+}$was the most abundant ion formed upon APCI of pentane, hexane, and cyclohexane (with nitrogen sheath gas), as expected [31], accompanied by only minor fragmentation. For example, pentane also formed ions of $\mathrm{m} / \mathrm{z} 57$ and 43, although their relative abundances are very low. Hence, the main reagent ion ionizing the analytes is the $[\mathrm{M}-\mathrm{H}]^{+}$ion.

For linear alkanes and 7-hexyloctadecane, the $[\mathrm{M}-\mathrm{H}]^{+}$ion, formed by hydride abstraction (Scheme 2), was found to be the only product ion upon APCI when employing pentane (Table S1 in Supplemental Information) or hexane as the reagents. LQIT/FT-ICR, which has a much higher resolution than LQIT, was employed to confirm that the $[\mathrm{M}-\mathrm{H}]^{+}$ion was the only ion formed at that nominal mass (Figure 1). Ionization of linear saturated hydrocarbons by employing cyclohexane as the reagent, instead of pentane or hexane, resulted in very low abundance of the $[\mathrm{M}-\mathrm{H}]^{+}$ions with extensive fragmentation. This is rationalized by the greater internal energy that cyclohexane molecular ions (and hence also their $[\mathrm{M}-\mathrm{H}]^{+}$ fragment ions) gain upon ionization of cyclohexane with nitrogen molecular ions (formed upon corona discharge ionization of the nitrogen sheath gas) due to cyclohexane's lower ionization energy (IE) $(9.9 \mathrm{eV})$ than that of pentane $(10.3$ $\mathrm{eV})$ and hexane (10.1 eV) [32].

For squalane, the most highly branched alkane studied, the $[\mathrm{M}-2 \mathrm{H}]^{+\bullet}$ product ion was prominently formed upon APCI using pentane (Table S1 in Supplemental Information), hexane, or cyclohexane as the reagents, with minor fragmentation. This is different from the linear saturated hydrocarbons, which form the $[\mathrm{M}-\mathrm{H}]^{+}$ion.

5 - $\alpha$-Cholestane, a polycyclic alkane with an alkyl side chain, formed abundant $[\mathrm{M}-\mathrm{H}]^{+}$and $\mathrm{M}^{+\bullet}$ ions when employing pentane (Table S1 in Supplemental Information) and hexane as the APCI ionization reagents, with minor fragmentation (an ion of $\mathrm{m} / \mathrm{z} 218$ ). However, when cyclohexane was used as the solvent and reagent, only $\mathrm{M}^{+\bullet}$ (with the fragment ion of $\mathrm{m} / \mathrm{z} 218,12 \%$ ) was observed.

4,7-Diphenyl-1,10-phenanthroline, chrysene, and squalene, which are highly unsaturated compounds, formed mainly the $[\mathrm{M}+\mathrm{H}]^{+}$ion upon APCI using pentane (Table S1 in Supplemental Information), hexane, and cyclohexane reagents. Chrysene also formed $\mathrm{M}^{+\bullet}$ and an ion/molecule reaction product, $\left[\mathrm{M}+\mathrm{H}+\mathrm{C}_{3} \mathrm{H}_{2}\right]^{+}$. Squalene also formed $[\mathrm{M}-\mathrm{H}]^{+}, \mathrm{M}^{+\bullet}$, and $\left[\mathrm{M}+\mathrm{H}+\mathrm{C}_{5} \mathrm{H}_{10}\right]^{+}$, as well as some fragment ions. Hence, this ionization method does not work as well for unsaturated as for saturated hydrocarbons.

Polar compounds, such as steroids and lignin monomer model compounds, were tested to probe the limits of this method by using pentane reagent. Androsterone, dihydrocholesterol, and 4-hydroxy-3-methoxybenzaldehyde formed abundant ions that provide molecular weight information, such as $\mathrm{M}^{+\bullet}$ and $[\mathrm{M}+\mathrm{H}]^{+}$(Table $\mathrm{S} 1$ in Supplemental Information). However, this method did not work well for the other steroids and lignin monomer model compounds studied. Some generated no ions due to their poor solubility in hydrocarbon solvents, and others generated very abundant fragment ions via loss of one or two water molecules from the protonated molecule (i.e., $[\mathrm{M}+\mathrm{H}-$ $\left.\mathrm{H}_{2} \mathrm{O}\right]^{+}$and $\left[\mathrm{M}+\mathrm{H}-2 \mathrm{H}_{2} \mathrm{O}\right]^{+}$.

The main complication of the method described here is that different types of compounds form different ions, such as $\mathrm{M}^{+\bullet},[\mathrm{M}-\mathrm{H}]^{+},[\mathrm{M}-2 \mathrm{H}]^{+\bullet},[\mathrm{M}+\mathrm{H}]^{+}$, which hinders obtaining the molecular weight information. In order to test whether it is possible to differentiate the odd-electron from the even-electron product ions when analyzing unknown compounds, dimethyl disulfide was added into the solution of model compounds prior to mass spectrometric analysis for reactions in the ion source region, or the ions of interest

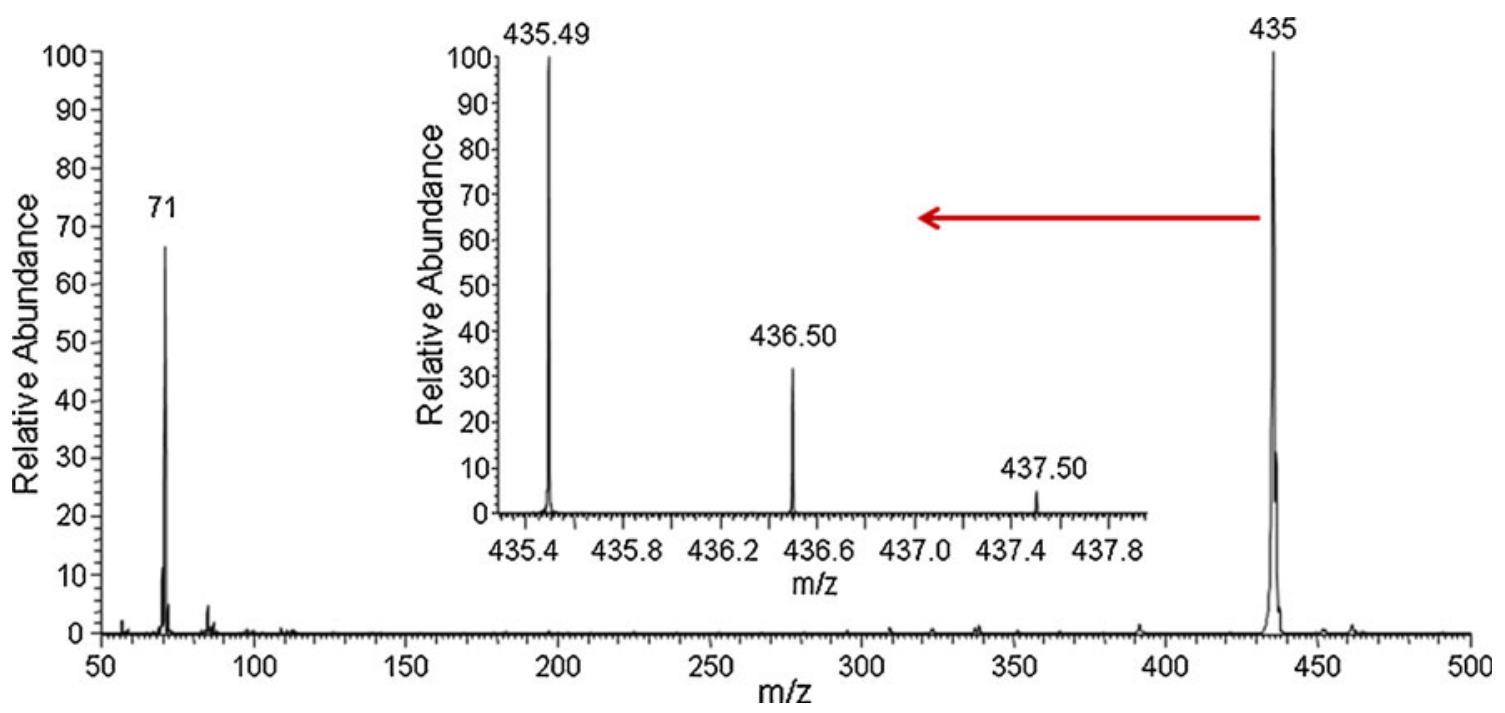

Figure 1. APCl/pentane mass spectrum of $n$-hentriacontane (MW 436) measured by using LQIT. The insert shows a high resolution spectrum measured by LQIT/FT-ICR. The peaks of $\mathrm{m} / \mathrm{z} 436.50$ and 437.50 correspond to isotopologues of $n$ hentriacontane 
were isolated and allowed to undergo ion/molecule reactions with dimethyl disulfide in the trap. Radical cations, such as $[\mathrm{M}-2 \mathrm{H}]^{+\bullet}$ and $\mathrm{M}^{+\bullet}$, are expected to react with dimethyl disulfide by electron abstraction (if they have a conventional structure and ionization energy greater than that of dimethyl disulfide; $8.2 \mathrm{eV}$ ) [33] or $\mathrm{SCH}_{3}$ abstraction (if they have a distonic structure [34-36]), while even-electron ions should be unreactive. For all analytes, dimethyl disulfide radical cation was formed in the ion source, probably due to ionization of dimethyl disulfide by the radical cation of the sheath gas $\left(\mathrm{N}_{2}\right)$. Hence, observation of the dimethyl disulfide radical cation in the ion source is not structurally informative. The $[\mathrm{M}-\mathrm{H}]^{+}$ions formed from linear saturated hydrocarbons did not undergo ion/molecule reactions with dimethyl disulfide in the trap, as expected. The $[\mathrm{M}-2 \mathrm{H}]^{+\cdot}$ ion formed from squalane was found to react with dimethyl disulfide by electron abstraction in the trap (Figure S1 in Supplemental Information), which not only reveals that it is a radical cation but also that it has a conventional structure. The $\mathrm{M}^{+\bullet}$ of squalene did not react with dimethyl disulfide in the trap. This is likely explained by its lower IE than that of dimethyl disulfide. Although the IE of squalene is not known, it is expected to be less than $8.0 \mathrm{eV}$ since similar but substantially smaller branched alkenes, such as 4-ethyl-3-methyloct-3-ene (MW 154; IE = $8.04 \mathrm{eV}$ [32]), have lower IEs than dimethyl disulfide. The $\mathrm{M}^{+\cdot}$ of $\alpha$-cholestane could not be transferred intact into the ion trap and hence could not be studied there. However, a low abundance of the $\left[\mathrm{M}+\mathrm{SCH}_{3}\right]^{+}$ion was found when the $\mathrm{M}^{+\bullet}$ of 5- $\alpha$-cholestane reacts with dimethyl disulfide in the ion source, which indicates the presence of a molecular ion that has isomerized to a distonic ion. Similarly, the $\mathrm{M}^{+\bullet}$ ion of squalene reacts with dimethyl disulfide by $\mathrm{SCH}_{3}$ abstraction in the ion source, which indicates that this molecular ion also has a distonic structure, formed possibly as shown in Scheme 1. Upon CAD, the $\left[\mathrm{M}+\mathrm{SCH}_{3}\right]^{+}$ion showed loss of $\mathrm{HSCH}_{3}$ (Figures S2 and S3 in Supplemental Information).This reaction can be used to verify that a product indeed is a $\mathrm{SCH}_{3}$ abstraction product.

Above results suggest that dimethyl disulfide can be used to differentiate radical cations from even-electron ions. Hence, it is possible to identify an ion as being either $\mathrm{M}^{+\bullet} /[\mathrm{M}-2 \mathrm{H}]^{+\bullet}$ or $[\mathrm{M}+\mathrm{H}]^{+} /[\mathrm{M}-\mathrm{H}]^{+}$, which facilitates MW determination.
Finally, the effect of the type of sheath gas on the ionization of $n$-dotriacontane upon APCI using pentane reagent was examined (Figure S4 in Supplemental Information). Helium sheath gas was found to cause some fragmentation $\left([\mathrm{M}-\mathrm{alkyl}]^{+}\right)$while carbon dioxide and nitrogen sheath gases showed no fragmentation. This can be explained by the pathways shown in Scheme 2 . $\mathrm{He}^{+\bullet}$ transfers more energy into a solvent molecule to form the ultimate reagent ion that ionizes the analyte, $\left[\mathrm{M}_{\text {pentane }}-\mathrm{H}\right]^{+}$, than $\mathrm{CO}_{2}{ }^{+\bullet}$ and $\mathrm{N}_{2}{ }^{+\bullet}$ due to helium's higher ionization energy $(24.6 \mathrm{eV})$ than carbon dioxide's $(13.8 \mathrm{eV})$ or nitrogen's $(15.6 \mathrm{eV})$ [32].

In order to test the feasibility of using the above method in mixture analysis, two mixtures (all in equimolar ratios) were examined by using APCI/pentane. The first mixture consisted of 13 linear saturated hydrocarbons. The mass spectrum measured for this mixture shows mainly $[\mathrm{M}-\mathrm{H}]^{+}$ ions, as expected (Figure S5 in Supplemental Information). While the relative abundances of these ions do not exactly match the relative molar concentrations, they are still close when considering that the ionization energies and volatilities of the compounds vary. The second mixture consisted of five model compounds, $n$-hentriacontane, squalane, 5- $\alpha$ cholestane, 4,7-diphenyl-1,10-phenanthroline, and chrysene. The mass spectrum (Figure S6 in Supplemental Information) shows the same ions as formed for the individual analytes. While the relative abundances of the ions do not exactly match the relative molar concentrations, all analytes were successfully detected, in spite of their widely varying ionization energies, compositions, structures, and volatilities.

Finally, a base oil sample was examined (Figure S7 in Supplemental Information) by this method. This sample had been analyzed previously by our group using a different method [17]. The molecular weight distribution determined here agrees with that determined by using the earlier method, $\mathrm{ClMn}\left(\mathrm{H}_{2} \mathrm{O}\right)^{+}$chemical ionization combined with laserinduced acoustic desorption/Fourier-transform ion cyclotron resonance mass spectrometry [17], in spite of the observation that the method introduced here also caused some fragmentation.

Hexane is commonly used as the mobile phase in normalphase high-performance liquid chromatography (HPLC).

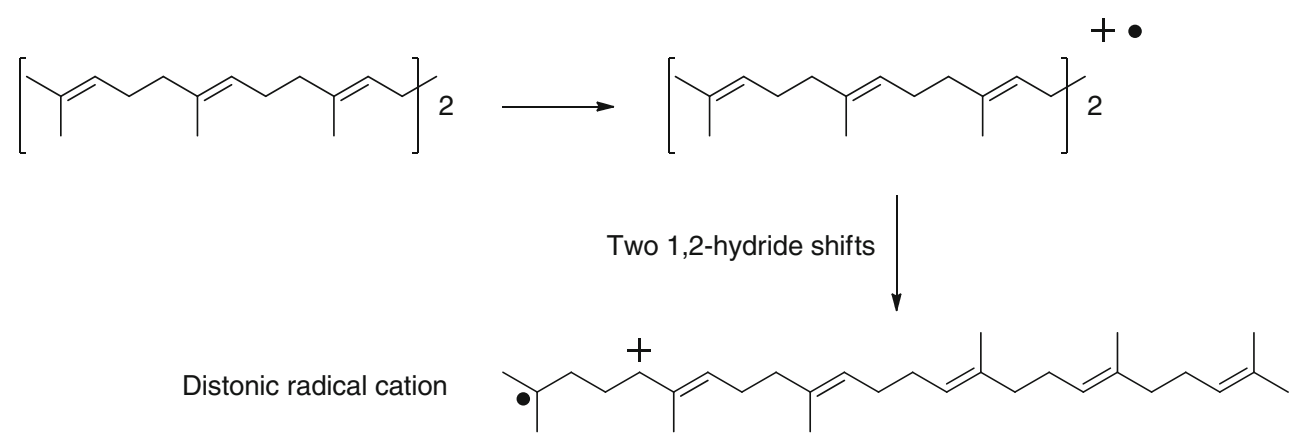

Scheme 1. A possible rearrangement of squalene molecular ion to a distonic isomer that is likely to be more stable due to resonance stabilization of the charge 


$$
\begin{aligned}
& \text { Sheath Gas } \stackrel{\text { Corona discharge }}{\longrightarrow} \text { Sheath Gas }{ }^{+\bullet} \\
& \text { Sheath } \mathrm{Gas}^{+\bullet}+\mathrm{M}_{\text {pentane }} \longrightarrow\left[\mathrm{M}_{\text {pentane }}{ }^{+\bullet}\right]^{*}+\text { Sheath Gas } \\
& {\left[\mathrm{M}_{\text {pentane }}^{+\cdot}\right]^{*} \longrightarrow \mathrm{C}_{3} \mathrm{H}_{7}^{+}+\mathrm{C}_{2} \mathrm{H}_{5}^{\cdot}} \\
& \mathrm{C}_{3} \mathrm{H}_{7}^{+}+\mathrm{M}_{\text {pentane }} \longrightarrow\left[\mathrm{M}_{\text {pentane }}-\mathrm{H}\right]^{+}+\mathrm{C}_{3} \mathrm{H}_{8} \\
& {\left[\mathrm{M}_{\text {pentane }} \mathrm{H}\right]^{+}+\mathrm{M}_{\text {analyte }} \longrightarrow\left[\mathrm{M}_{\text {analyte }}-\mathrm{H}\right]^{+}+\mathrm{M}_{\text {pentane }}+\text { fragment ions }}
\end{aligned}
$$

Scheme 2. Possible pathways for the formation of $\left[\mathrm{M}-\mathrm{H}^{+}\right.$ions and their fragment ions

Hence, the ionization method discussed here can be readily coupled with normal-phase HPLC. The feasibility of this experiment was tested by separating an artificial mixture of $n$ dotriacontane (linear saturated hydrocarbon), chrysene (polyaromatic hydrocarbon), and 4,7-diphenyl-1,10-phenanthroline (heteroaromatic compound) by reversed phase HPLC, using hexane as the mobile phase, prior to analysis via APCI using hexane as the CI reagent (Figure 2). Each separated compound's HPLC mass spectrum matched its corresponding spectrum obtained from the direct injection of the single model compound.

\section{Conclusions}

APCI employing pentane, hexane, or cyclohexane as the solvent/reagent in APCI mass spectrometry allows the ionization of linear and branched saturated hydrocarbons

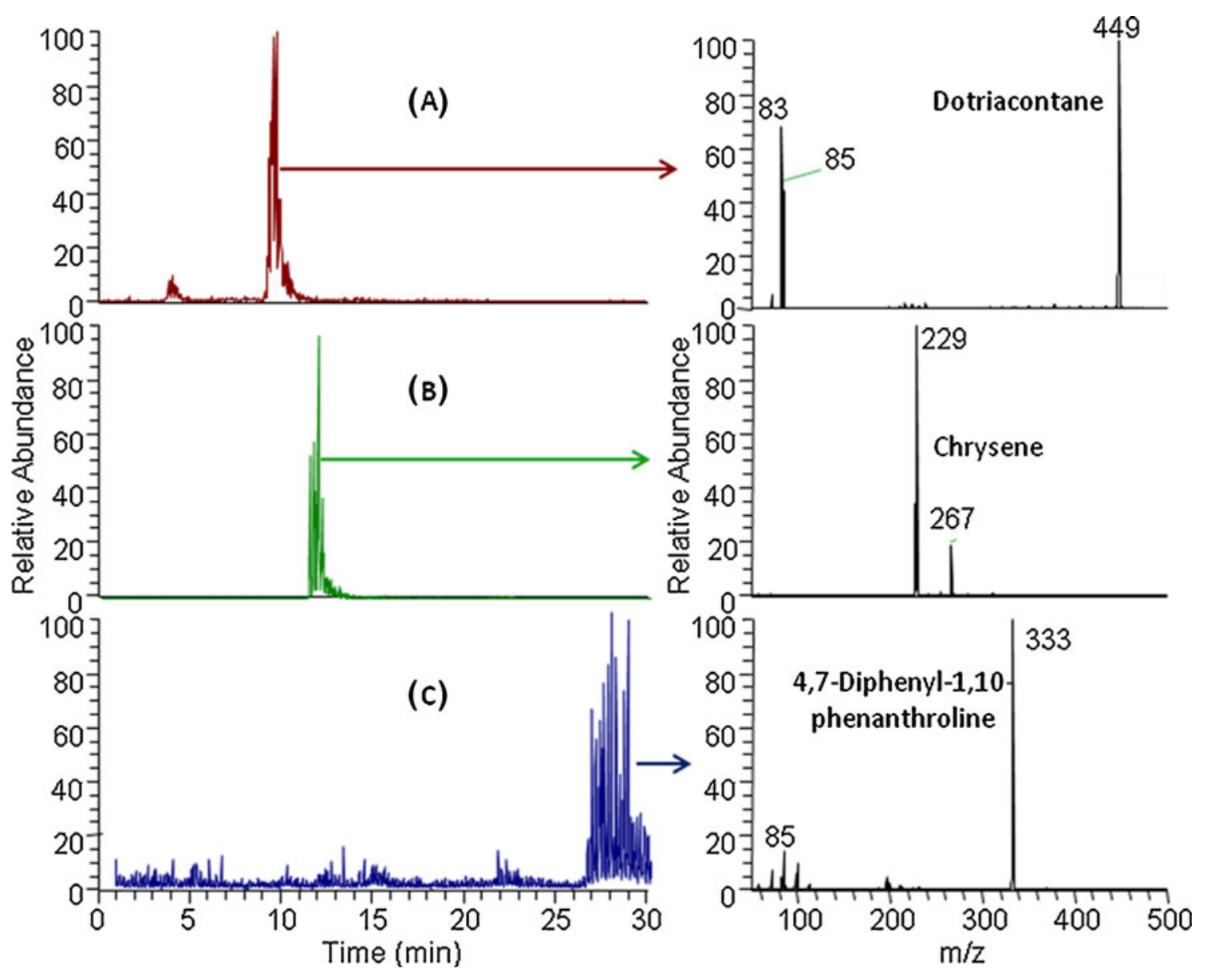

Figure 2. Extracted single ion chromatograms (ions of $m / z 449,229$, and 333) for $n$-dotriacontane (A), chrysene (B), and 4,7diphenyl-1,10-phenanthroline (C) (left) and the full APCl/pentane mass spectra measured for $n$-dotriacontane (MW 450), chrysene (MW 228) and 4,7-diphenyl-1,10-phenanthroline (MW 332) (right) 
(e.g., 7-hexyloctadecane) to yield an abundant $[\mathrm{M}-\mathrm{H}]^{+}$ion without fragmentation. Highly branched alkanes produce $[\mathrm{M}-2 \mathrm{H}]^{+\bullet}$ as the most abundant ion. Highly unsaturated hydrocarbons yield mostly $[\mathrm{M}+\mathrm{H}]^{+}$. Both $\mathrm{M}^{+\bullet}$ and $[\mathrm{M}-\mathrm{H}]^{+}$ ions (and a fragment ion of $m / z 218$ ) are formed for $5-\alpha$ cholestane when employing pentane or hexane. However, when using cyclohexane, only the molecular ion (and a fragment ion of $m / z 218$ ) is formed for 5- $\alpha$-cholestane. Dimethyl disulfide reagent can be used to differentiate radical cations from evenelectron cations, which facilitates MW determination.

This method allowed the ionization of some steroids, such as androsterone, and lignin monomer model compounds, such as 4-hydroxy-3-methoxybenzaldehyde, which formed abundant ions such as $\mathrm{M}^{+\bullet}$ and $[\mathrm{M}+\mathrm{H}]^{+}$, although fragment ions were also formed. However, other steroids and lignin monomer model compounds studied did not generate any product ions due to their poor solubility in hydrocarbon solvents, or generated product ions that had lost one or two water molecules after protonation, $\left[\mathrm{M}+\mathrm{H}-\mathrm{H}_{2} \mathrm{O}\right]^{+}$ and $\left[\mathrm{M}+\mathrm{H}-2 \mathrm{H}_{2} \mathrm{O}\right]^{+}$.

All analytes in two known mixtures were successfully detected in a single experiment, in spite of their widely varying ionization energies, compositions, structures, and volatilities. Further, the molecular weight distribution determined for a base oil sample is in good agreement with that determined by another method, laser-induced acoustic desorption/chemical ionization/Fourier-transform ion cyclotron resonance mass spectrometry [17].

The method described here has several advantages. As opposed to ESI and MALDI-based methods, nonpolar compounds (including linear saturated hydrocarbons) can be analyzed. Further, this method can be easily coupled with HPLC, thus enabling rapid analysis of a large number of different samples without pre-separation or derivatization. Finally, the analysis can be done on any mass spectrometer equipped with an APCI source. Implementation of this methodology to analyze biofuels is in progress.

\section{Acknowledgments}

This research was supported as part of the Center for Direct Catalytic Conversion of Biomass to Biofuels (C3Bio), an Energy Frontier Research Center funded by the U.S. Department of Energy, Office of Science.

\section{References}

1. Luque, R., Herrero-Davila, L., Campelo, J.M., Clark, J.H., Hidalgo, J. M., Luna, D., Marinas, J.M., Romero, A.A.: Biofuels: A Technological Perspective. Energy Environ. Sci. 1, 542-564 (2008)

2. Demirbas, A.: Political, Economic and Environmental Impacts of Biofuels: A Review. Appl. Energy 86, S108-S117 (2009)

3. Demain, A.L.: Biosolutions to the Energy Problem. J. Ind. Microbiol. Biotechnol. 36, 319-332 (2009)

4. Joseph, J., Baker, C., Mukkamala, S., Beis, S.H., Wheeler, M.C., DeSisto, W.J., Jensen, B.L., Frederick, B.G.: Chemical Shifts and Lifetimes for Nuclear Magnetic Resonance (NMR) Analysis of Biofuels. Energy Fuel 24, 5153-5162 (2010)
5. Mahamuni, N., Adewuyi, Y.G.: Fourier Transform Infrared Spectroscopy (FTIR) Method to Monitor Soy Biodiesel and Soybean Oil in Transesterification Reactions, Petrodiesel-Biodiesel Blends, and Blend Adulteration with Soy Oil. Energy Fuel 23, 3773-3782 (2009)

6. Yang, Z., Hollebone, B.P., Wang, Z., Yang, C., Landriault, M. Determination of Polar Impurities in Biodiesels Using Solid-Phase Extraction and Gas Chromatography-Mass Spectrometry. J. Sep. Sci. 34, 409-421 (2011)

7. Madl, T., Mittelbach, M.: Quantification of Primary Fatty Acid Amides in Commercial Tallow and Tallow Fatty Acid Methyl Esters by HPLCAPCI-MS. Analyst 130, 565-570 (2005)

8. Steinbach, A.; Wille, A.; Subramanian, N. H. Biofuel Analysis by Ion Chromatography. LC-GC Eur. 2008, 35-38.

9. Smith, J.S., Laskin, A., Laskin, J.: Molecular Characterization of Biomass Burning Aerosols Using High-Resolution Mass Spectrometry. Anal. Chem. 81, 1512-1521 (2009)

10. Eberlin, L.S., Abdelnur, P.V., Passero, A., Sa, G.F., Daroda, R.J., Souza, V., Eberlin, M.N.: Analysis of Biodiesel and BiodieselPetrodiesel Blends by High Performance Thin Layer Chromatography Combined with Easy Ambient Sonic-Spray Ionization Mass Spectrometry. Analyst 134, 1652-1657 (2009)

11. Alberici, R.M., Simas, R.C., Souza, V., Sá, G.F., Daroda, R.J., Eberlin, M.N.: Analysis of Fuels via Easy Ambient Sonic-Spray Ionization Mass Spectrometry. Anal. Chim. Acta 659, 15-22 (2010)

12. Fenn, J.B., Mann, M., Meng, C.K., Wong, S.F., Whitehouse, C.M.: Electrospray Ionization-Principles and Practice. Mass Spectrom. Rev. 9, 37-70 (1990)

13. Tanaka, K., Waki, H., Ido, Y., Akita, S., Yoshida, Y., Yoshida, T.: Protein and Polymer Analyses up to $\mathrm{m} / \mathrm{z} 100000$ by Laser Ionization Time-of-flight Mass Spectrometry. Rapid Commun. Mass Spectrom. 2, $151-153$ (1988)

14. Souverain, S., Rudaz, S., Veuthey, J.L.: Matrix Effect in LC-ESI-MS and LC-APCI-MS with Off-line and On-line Extraction Procedures. $J$. Chromatogr. A 1058, 61-66 (2004)

15. Ismaiel, O.A., Halquist, M.S., Elmamly, M.Y., Shalaby, A., Karnes, H. T.: Monitoring Phospholipids for Assessment of Ion Enhancement and Ion Suppression in ESI and APCI LC/MS/MS for Chlorpheniramine in Human Plasma and the Importance of Multiple Source Matrix Effect Evaluations. J. Chromatogr. B 875, 333-343 (2008)

16. Duan, P.G., Fu, M.K., Pinkston, D.S., Habicht, S.C., Kenttämaa, H.I.: Gas-Phase Reactions of ClMn(H2O) ${ }^{+}$with Polar and Nonpolar Hydrocarbons in a Mass Spectrometer. J. Am. Chem. Soc. 129, 9266-9267 (2007)

17. Duan, P., Qian, K., Habicht, S.C., Pinkston, D.S., Fu, M., Kenttämaa, H.I.: Analysis of Base Oil Fractions by $\mathrm{ClMn}(\mathrm{H} 2 \mathrm{O})^{+}$Chemical Ionization Combined with Laser-Induced Acoustic Desorption/Fourier Transform Ion Cyclotron Resonance Mass Spectrometry. Anal. Chem. 80, 1847-1853 (2008)

18. Marshall, A.G., Rodgers, R.P.: Petroleomics: Chemistry of the Underworld. Proc. Natl. Acad. Sci. U.S.A. 105, 18090-18095 (2008)

19. Wu, C., Qian, K., Nefliu, M., Cooks, G.R.: Ambient Analysis of Saturated Hydrocarbons Using Discharge-Induced Oxidation in Desorption Electrospray Ionization. J. Am. Soc. Mass Spectrom. 21, 261-267 (2010)

20. Ludányi, K., Dallos, A., Kühn, Z., Vékey, K.: Mass Spectrometry of Very Large Saturated Hydrocarbons. J. Mass Spectrom. 34, 264-267 (1999)

21. Liang, Z., Hsu, C.S.: Molecular Speciation of Saturates by On-Line Liquid Chromatography-Field Ionization Mass Spectrometry. Energy Fuel 12, 637-643 (1998)

22. Purcell, J.M., Hendrickson, C.L., Rodgers, R.P., Marshall, A.G.: Atmospheric Pressure Photoionization Fourier Transform Ion Cyclotron Resonance Mass Spectrometry for Complex Mixture Analysis. Anal. Chem. 78, 5906-5912 (2006)

23. Horning, E.C., Horning, M.G., Carroll, D.I., Dzidic, I., Stillwel, R.N.: New picogram detection system based on a mass spectrometer with an external ionization source at atmospheric pressure. Anal. Chem. 45, 936-943 (1973)

24. Sunner, J., Nicol, G., Kebarle, P.: Factors Determining Relative Sensitivity of Analytes in Positive Mode Atmospheric Pressure Ionization Mass Spectrometry. Anal. Chem. 60, 1300-1307 (1988)

25. Herrera, L.C., Grossert, J.S., Ramaley, L.: Quantitative Aspects of and Ionization Mechanisms in Positive-Ion Atmospheric Pressure Chemical Ionization Mass Spectrometry. J. Am. Soc. Mass Spectrom. 19, 1926$1941(2008)$ 
26. Dzidic, I., Carroll, D.I., Stillwell, R.N., Horning, E.C.: Comparison of Positive Ions Formed in Nickel-63 and Corona Discharge Ion Sources Using Nitrogen, Argon, Isobutane, Ammonia and Nitric Oxide as Reagents in Atmospheric Pressure Ionization Mass Spectrometry. Anal. Chem. 48, 1763-1768 (1976)

27. Gao, J., Borton, D.J.II., Owen, B.C., Jin, Z., Hurt, M., Amundson, L. M., Madden, J.T., Qian, K., Kenttämaa, H.I.: Laser-Induced Acoustic Desorption/Atmospheric Pressure Chemical Ionization Mass Spectrometry. J. Am. Soc. Mass Spectrom. 22, 531-538 (2011)

28. Owen, B.C., Gao, J., Borton II, D.J., Amundson, L.M., Archibold, E.F., Tan, X., Azyat, K., Tykwinski, R., Gray, M., Kenttämaa, H.I.: Carbon Disulfide Reagent Allows the Characterization of Nonpolar Analytes by Atmospheric Pressure Chemical Ionization Mass Spectrometry. Rapid. Commun. Mass Spectrom. 5, 1924-1928 (2011)

29. Yang, Z., Attygalle, A.B.: Aliphatic Hydrocarbon Spectra by Helium Ionization Mass Spectrometry (HIMS) on a Modified AtmosphericPressure Source Designed for Electrospray Ionization. J. Am. Soc. Mass Spectrom. 22, 1395-1402 (2011)

30. Corma, A., Torre, O., Renz, M., Villandier, N.: Production of HighQuality Diesel from Biomass Waste Products. Angew. Chem. Int. Ed. 50, 2375-2378 (2011)
31. Marotta, E., Paradisi, C.: A Mass Spectrometry Study of Alkanes in Air Plasma at Atmospheric Pressure. J. Am. Soc. Mass Spectrom. 20, 697707 (2009)

32. Lindstrom, P. J.; Mallard, W. G (Eds.) NIST Chemistry WebBook, NIST Standard Reference Database Number 69. National Institute of Standards and Technology, Gaithersburg, MD, 20899, http://webook. nist.gov (accessed January 6, 2011).

33. Leeck, D.T., Kenttamaa, H.I.: Heat of Formation of the Radical Cation of Dimethyl Disulfide. Org. Mass Spectrom. 29, 106-107 (1994)

34. Stirk, K.M., Orlowski, J.C., Leeck, D.T., Kenttämaa, H.I.: The Identification of Distonic Radical Cations on the Basis of a Reaction with Dimethyl Disulfide. J. Am. Chem. Soc. 114, 86048606 (1992)

35. Smith, R.L., Chyall, L.J., Stirk, K.M., Kenttämaa, H.I.: Radical-type Reactivity of the Methylenedimethylsulfonium Ion, $\left(\mathrm{CH}_{3}\right)_{2} \mathrm{~S}^{+}-\mathrm{CH} 2$. Org. Mass Spectrom. 28, 1623-1631 (1993)

36. Smith, R.L., Schweighofer, A., Keck, H., Kuchen, W., Kenttämaa, H.I.: Unusual Reactivity of the Radical Cations of Some Simple Trivalent Organophosphorus Compounds toward Dimethyl Disulfide and Dimethyl Diselenide. J. Am. Chem. Soc. 118, 1408-1412 (1996) 